\title{
Los principios de la bioética y el surgimiento de una bioética intercultural
}

\author{
JUAN CARLOS SIURANA APARISI \\ Universidad de Valencia (España) \\ juan.c.siurana@uv.es
}

\begin{abstract}
Resumen
En este trabajo defiendo que el debate internacional sobre los principios de la bioética es uno de los más fructíferos para construir los fundamentos de una bioética intercultural. Tras recordar en qué consisten los principios de la bioética, tal y como han sido defendidos por Tom L. Beauchamp y James F. Childress en Estados Unidos, ofrezco una breve mirada a estos principios desde Europa, América Latina, África y Asia. Continúo con una reflexión sobre dichos principios desde algunas de las grandes religiones del mundo. Todo ello me permite ofrecer importantes elementos para construir las bases de lo que podríamos llamar una «bioética intercultural».
\end{abstract}

Palabras claves: principios de la bioética, bioética intercultural, Beauchamp, Childress, religiones.

\section{The principles of bioethics and the growth of an intercultural bioethics}

\begin{abstract}
In this article I defend that the international debate on de principles of bioethics is one of the most fruitful to build the foundation of an intercultural bioethics. I make here a brief summary on the content of the "principles of biomedical ethics» as they were defended by Tom L. Beauchamp and James F. Childress in the United States. Afterwords, I provide a brief perspective of these principles from Europe, Latinamerica, Africa and Asia. I follow with a reflection on such principles from some of the big religions of the world. All of that, permits me to provide important elements to build the basis of wath we could call an «intercultural bioethics».
\end{abstract}

Key words: principles of bioethics, intercultural bioethics, Beauchamp, Childress, religions.

Doctor Europeo en Filosofía en la Universidad de Valencia (España). Realizó estudios de postgrado en la Universidad de Francfort (Alemania), con una beca del DAAD, y estancias de investigación en centros de Europa y América. Investigador de la Fundación General de la Universidad de Valencia y profesor en las áreas de Filosofía Moral y Filosofía Política de esta universidad. Director del Grupo de Investigación en Bioética de la Universidad de Valencia (http://www.uv.es/gibuv). Es autor de los libros: Una bríjula para la vida moral (2003), Voluntades anticipadas. Una alternativa a la muerte solitaria (2005) y La sociedad ética. Indicadores para evaluar éticamente una sociedad (2009).

Este trabajo se inscribe dentro del proyecto de investigación FFI2008-06133/FISO subvencionado por el Ministerio de Ciencia e Innovación. También se inserta en las actividades del grupo de investigación de excelencia PROMETEO /2009/085 de la Generalitat Valenciana. 


\section{Introducción}

El debate sobre los principios de la bioética se inicia en el año 1974, cuando el Congreso de los Estados Unidos crea la Comisión Nacional para la Protección de los Sujetos Humanos de Investigación Biomédica y del Comportamiento, para identificar los principios éticos básicos que deben regir la investigación con seres humanos en la medicina y las ciencias de la conducta. En 1978 los comisionados publican el «Informe Belmont»", donde distinguen tres principios éticos básicos, por este orden: respeto por las personas, beneficencia y justicia.

Pero el «Informe Belmont» sólo se refiere a las cuestiones éticas surgidas en el ámbito de la investigación clínica, y más concretamente en la experimentación con seres humanos. Tom L. Beauchamp, miembro de la Comisión Nacional, y James F. Childress, en su famoso libro Principios de ética biomédica ${ }^{2}$ - publicado por primera vez en 1979 y revisado en cuatro ocasiones-, reformulan estos principios para ser aplicados a la ética asistencial. Estos autores, al igual que la Comisión Nacional, al ordenar la exposición de los principios, colocan en primer lugar el de autonomía, probablemente por las nefastas consecuencias conocidas por no respetarlo, aunque, a nivel práctico, no establecen ninguna jerarquía entre ellos. Beauchamp y Childress distinguen cuatro principios: no maleficencia, beneficencia, autonomía y justicia.

A partir de entonces, los autores que han participado en el debate internacional sobre los fundamentos de la bioética no han podido evitar tomar posición frente a los principios de la bioética.

A continuación voy a recordar en qué consisten los principios de la bioética, tal y como han sido defendidos por Tom L. Beauchamp y James F. Childress en Estados Unidos, y luego, ofreceré una breve mirada a estos principios desde Europa, América Latina, África y Asia. Continuaré con una reflexión sobre dichos principios partiendo del pensamiento de algunas de las grandes religiones del mundo. Todo ello me permitirá ofrecer importantes elementos para construir las bases de lo que podríamos llamar una «bioética intercultural».

Cfr. Comisión Nacional para la Protección de los Sujetos Humanos de Investigación Biomédica y del Comportamiento, "Informe Belmont de 30 de septiembre de 1978. Principios éticos y orientaciones para la protección de sujetos humanos en la experimentación", en M. CASADO (con la colaboración de S. Darío Bergel, M. Dobernig, G. Figueroa Yáñez y A. Sánchez Urrutia): Las leyes de la bioética. Gedisa, Barcelona 2004, 85-111.

2 Cfr. T. L. Beauchamp y J. F. Childress: Principles of Biomedical Ethics. Fourth Edition, Oxford University Press, Nueva York/Oxford 1994 (trad. cast. Principios de ética biomédica. Masson, Barcelona 1999). 


\section{Los principios de la bioética de Beauchamp y Childress en Estados Unidos}

El principialismo defiende que existen algunos principios generales descubiertos en el ámbito de la ética biomédica y que deben ser respetados cuando se plantean conflictos éticos en la investigación o en la práctica clínica.

Diego Gracia ha hecho una magistral exposición de la historia de estos principios desde la antigüedad clásica hasta la actualidad ${ }^{3}$. Aquí no nos centraremos tanto en cuestiones históricas cuanto en cuestiones conceptuales. Con ello pretendemos indagar cuáles son los elementos relevantes que puede ofrecer el enfoque principialista para fundamentar una bioética intercultural.

En Principles of Biomedical Ethics, Tom L. Beauchamp y James F. Childress, defienden los siguientes cuatro principios:

\subsection{Respeto de la autonomía}

La palabra «autonomía» proviene del griego y significa «autogobierno». Se usa por primera vez para referirse a la capacidad de autogobierno de las ciudades-estado griegas independientes.

Para Beauchamp y Childress, el individuo autónomo es el que «actúa libremente de acuerdo con un plan autoescogido» ${ }^{4}$. Según afirman estos autores, todas las teorías de la autonomía están de acuerdo en dos condiciones esenciales: a) la libertad, entendida como la independencia de influencias que controlen, y b) la agencia, es decir, la capacidad para la acción intencional.

Que un ser es autónomo no significa meramente que sigue sus propios deseos o inclinaciones. El alcohólico que quiere vencer su dependencia al alcohol siente deseos de beber pero trata de guiarse no por esos deseos inmediatos, sino por otros más acordes con los valores sobre la idea que tiene de sí mismo. Si recogemos el significado que algunas teorías dan a la persona autónoma encontramos los siguientes rasgos $^{5}$ : excepcionalmente auténtica, autoposeída, consistente, independiente, autogobernada, resistente al control por autoridades, y fuente original de los valores, creencias y planes de vida personales. Beauchamp

\footnotetext{
3 Cfr. D. GRACIA: Fundamentos de bioética. Eudema, Madrid 1989.

4 T. L. BeAuchamp y J. F. Childress: Principles of Biomedical Ethics. Fourth Edition, 121.

5 Cfr. G. Dworkin: The Theory and Practice of Autonomy. Cambridge University Press, Cambridge/Nueva York/Melbourne 1988, $3^{a}$ reimpr. 1995.
} 
y Childress entienden que ese ideal de autonomía es muy alto y que muy pocos pueden aspirar a alcanzarlo.

La autonomía es un concepto que admite grados, por eso, a Beauchamp y Childress, para tomar decisiones en casos clínicos, no les interesa tanto el concepto de autonomía como la noción de acción autónoma. Para estos autores, una acción es autónoma cuando el que actúa lo hace a) intencionadamente, b) con comprensión y c) sin influencias controladoras que determinen su acción. La intencionalidad no admite grados, la comprensión y la coacción sí. Para poder determinar si una acción es autónoma, tenemos que conocer si es o no intencional $\mathrm{y}$, además, comprobar si supera un nivel substancial de comprensión y de libertad de coacciones, y no si alcanza una total comprensión o una total ausencia de influencias. A estas acciones se las llama substancialmente autónomas, pero no completamente autónomas.

La autonomía de una persona es respetada cuando se le reconoce el derecho a mantener puntos de vista, a hacer elecciones y a realizar acciones basadas en valores y creencias personales. El respeto por la autonomía del paciente obliga a los profesionales a revelar información, a asegurar la comprensión y la voluntariedad y a potenciar la participación del paciente en la toma de decisiones.

Beauchamp y Childress nos dan algunas reglas para tratar a las personas de manera autónoma:

1. «Di la verdad».

2. «Respeta la privacidad de otros».

3. «Protege la confidencialidad de la información».

4. «Obtén consentimiento para las intervenciones a pacientes».

5. «Cuando te lo pidan, ayuda a otros a tomar decisiones importantes».

\subsection{No-maleficencia}

El principio de no-maleficencia hace referencia a la obligación de no infringir daño intencionadamente. Este principio se inscribe en la tradición de la máxima clásica primum non nocere («lo primero no dañar»). Aunque la máxima como tal no se encuentra en los tratados hipocráticos, sí que existe una obligación de no maleficencia expresada en el juramento hipocrático. Así, sobre el uso del régimen para el beneficio de los pacientes, este juramento dice: «si es para su daño (...) lo impediré» ${ }^{6}$.

6 HipÓCRATES: "Juramento", Tratados hipocráticos, 87. 
Algunos filósofos consideran a la no-maleficencia y la beneficencia como un mismo principio. Para Beauchamp y Childress la obligación de no dañar a otros, por ejemplo, no robar, no lastimar o no matar, es claramente distinta a la obligación de ayudar a otros, por ejemplo, ofrecer beneficios, proteger intereses o promover bienestar.

Este principio solicita «no dañar». Una persona daña a otra cuando lesiona los intereses de ésta. Estos intereses pueden considerarse de manera amplia como son los referidos a la reputación, la propiedad, la privacidad o la libertad. Definiciones más estrechas se refieren a intereses físicos y psicológicos, como la salud y la vida. Beauchamp y Childress en el diseño del principio de no-maleficencia se concentran en «los daños físicos, incluyendo el dolor, la discapacidad y la muerte, sin negar la importancia de los daños mentales y las lesiones de otros intereses»? En particular enfatizan las acciones que causan o que permiten la muerte o el riesgo de muerte.

Reglas típicas referidas al principio de no-maleficencia son las siguientes:

1. «No mate».

2. «No cause dolor o sufrimiento a otros».

3. «No incapacite a otros».

4. «No ofenda a otros».

5. «No prive a otros de aquello que aprecian en la vida».

\subsection{Beneficencia}

Si la no-maleficencia consiste en no causar daño a otros, la beneficencia consiste en prevenir el daño, eliminar el daño o hacer el bien a otros. Mientras que la no-maleficencia implica la ausencia de acción, la beneficencia incluye siempre la acción. Beauchamp y Childress distinguen dos tipos de beneficencia: la beneficencia positiva y la utilidad. La beneficencia positiva requiere la provisión de beneficios. La utilidad requiere un balance entre los beneficios y los daños.

En el lenguaje habitual, la beneficencia hace referencia a actos de buena voluntad, amabilidad, caridad, altruismo, amor o humanidad. La beneficencia puede entenderse, de manera más general, como todo tipo de acción que tiene por finalidad el bien de otros. Si la benevolencia se refiere a la voluntad de hacer el bien, con independencia de que se cumpla o no la voluntad, la beneficencia, en cambio, es un acto realizado

Cfr. T. L. Beauchamp y J. F. Childress: Principles of Biomedical Ethics. Fourth Edition, 193. 
por el bien de otros. Pero cuando Beauchamp y Childress hablan del principio de beneficencia ${ }^{8}$ no se refieren a todos los actos realizados para hacer el bien, sino sólo a aquellos actos que son una exigencia ética en el ámbito de la medicina. Según estos autores, antes de realizar un tratamiento sobre un paciente, estamos obligados a hacer un balance de sus beneficios y riesgos.

Algunos ejemplos de reglas de beneficencia son las siguientes:

1. Protege y defiende los derechos de otros.

2. Previene el daño que pueda ocurrir a otros.

3. Quita las condiciones que causarán daño a otros.

4. Ayuda a personas con discapacidades.

5. Rescata a personas en peligro.

Los autores dicen que el principio de beneficencia es una exigencia y no una mera invitación a la acción, por ello es importante distinguir en qué circunstancias hacer el bien es una exigencia. Según ellos, asumiendo que la persona $\mathrm{X}$ es consciente de los hechos relevantes, entonces $\mathrm{X}$ tiene la obligación de beneficencia hacia la persona $\mathrm{Y}$ si y sólo si se satisfacen cada una de las siguientes condiciones:

a) Y está en peligro de perder la vida o recibir un daño significativo en su salud o en algunos otros intereses importantes.

b) La acción de $\mathrm{X}$ se necesita, de modo singular o en unión con otros, para prevenir esta pérdida o daño.

c) La acción de $\mathrm{X}$, de modo singular o en unión con otros, tiene una alta probabilidad de prevenir esta pérdida o daño.

d) La acción de $\mathrm{X}$ no representa riesgos, costes o cargas significativas para $\mathrm{X}$.

e) El beneficio que se puede esperar que gane $Y$ sobrepasa a todos los daños, costes o cargas que pueden afectar a X.

Cuando la beneficencia se practica sin considerar la opinión del paciente, se incurre en el paternalismo.

\subsection{Justicia}

Las desigualdades en el acceso al cuidado de la salud y el incremento de los costes de estos cuidados han ocasionado en el ámbito de la sanidad el debate sobre la justicia social. La máxima clásica de Ulpiano

8 Cfr. ibíd., 260. 
dice que la justicia consiste en «dar a cada uno lo suyo». De un modo similar, Beauchamp y Childress entienden que la justicia es el tratamiento equitativo y apropiado a la luz de lo que es debido a una persona. Una injusticia se produce cuando se le niega a una persona el bien al que tiene derecho o no se distribuyen las cargas equitativamente.

El término relevante en este contexto es el de justicia distributiva que, según estos autores, se refiere a «la distribución imparcial, equitativa y apropiada en la sociedad, determinada por normas justificadas que estructuran los términos de la cooperación social» ${ }^{9}$. Sus aspectos incluyen las políticas que asignan beneficios diversos y cargas tales como propiedad, recursos, privilegios y oportunidades. Son varias las instituciones públicas y privadas implicadas, incluyendo al Gobierno y al sistema sanitario.

Los problemas de la justicia distributiva aumentan bajo condiciones de escasez y competición. Se han propuesto varios criterios de distribución: a) a cada persona una participación igual, b) a cada persona de acuerdo con sus necesidades individuales, c) a cada persona de acuerdo a sus esfuerzos individuales, d) a cada persona de acuerdo a su contribución social, y e) a cada persona de acuerdo con sus méritos.

Sobre el principio de justicia en ética biomédica un autor especialmente relevante es Norman Daniels ${ }^{10}$. Este autor nos dice que existe un conflicto de intereses entre los que precisan servicios de salud y los que soportan sus gastos, pero incluso en Estados Unidos, que no es un Estado de bienestar, se piensa que los cuidados de la salud deben distribuirse más igualitariamente que otros bienes. Daniels se pregunta qué tiene de especial el cuidado de la salud. Daniels entiende que la sociedad tiene la obligación de proteger la igualdad de oportunidades de todos sus miembros. Por eso hay que examinar las implicaciones que se siguen para las instituciones sanitarias, pues han de reformarse si no son capaces de garantizar esa igualdad de oportunidades, que viene potenciada por el acceso igualitario a los cuidados de la salud.

Ibíd., 327.

10 Cfr. N. Daniels: Just Health Care. Cambridge University Press, Cambridge/Nueva York/Melburne 1985, $5^{\text {a }}$ reimpr. 1995. 


\section{Una mirada a los principios de la bioética desde Europa, América Latina, África y Asia}

\subsection{Los principios de la bioética del Consejo de Europa}

En Europa hay una gran diversidad de culturas que se muestra en las diferencias existentes entre las instituciones de los diversos países, los modelos de pensamiento, y los modelos de trabajo. Así, por ejemplo, según David Shapiro, en el Reino Unido y Holanda hay una larga tradición de pluralismo en las estructuras de las instituciones que están a la base de la ética biomédica, mientras que las instituciones francesas están mucho más centralizadas. Pero la diversidad de las tradiciones políticas, jurídicas y profesionales no son un obstáculo para su armonización dentro de la Unión Europea. «Para alcanzar una armonización sobre los principios éticos que deben regir en los países individuales, hay ya una manera institucional de proceder del Consejo de Europa, así como contribuciones de parte del Parlamento Europeo» ${ }^{11}$.

Hablando sobre la función del Consejo de Europa para el diseño de los principios de la ética biomédica, Octavi Quintana-Trias señala algunas diferencias y similitudes entre los países europeos. Así, nos dice que aunque existen diferencias en los sistemas de salud nacionales, tienen en común el hecho de ofrecer servicios sanitarios básicos para todos los ciudadanos. Se produce alguna diferencia sobre la importancia que se concede al principio de autonomía. Según Quintana-Trias, «en los países del norte de Europa el respeto a la autonomía del paciente tiene una larga tradición, mientras que en los países mediterráneos a menudo la familia toma la decisión en nombre del paciente» ${ }^{12}$. A pesar de estas diferencias, los problemas éticos planteados son, en general, los mismos. Aunque la tradición sea más o menos larga, lo cierto es que todos los países europeos cuentan en nuestros días con sociedades pluralistas.

Uno de los obstáculos más importantes para armonizar los principios que deben regir ante los problemas de ética biomédica en los diversos países de Europa es que ningún país acepta en la actualidad la intromisión en sus sistemas nacionales de salud. Quintana-Trias dice: «Las cuestiones de la distribución de los recursos y los problemas éticos unidos a ellas son comunes a la mayoría de los países, pero se consideran

11 D. SHAPIRO: "Medizinische Ethik in Grossbritannien: Ansätze und Principien in Ethik und Recht", Jabrbuch für Wissenschaft und Ethik, vol. 1 (1996), 177.

12 O. QuintANA-TRIAS: "Internationale Bioethik: Die Rolle des Europarates", Jabrbuch für Wissenschaft und Ethik, vol. 1 (1996), 197. 
exclusivamente como asuntos nacionales $»^{13}$. En la actualidad la armonización de criterios se está consiguiendo en cuestiones relativas a la aplicación de la tecnología médica, ámbito donde la ética biomédica se muestra defensiva en tanto que ve amenazada la dignidad de los hombres y los derechos humanos. El Consejo de Europa ha producido varios documentos sobre ética biomédica, empezando por documentos relativos a los derechos de los pacientes y los moribundos, y pasando por diversos aspectos de la reproducción, la investigación y la genética. También el Parlamento Europeo ofrece documentos de este tipo. Los textos ofrecen consideraciones generales, ya que es muy difícil el consenso sobre cuestiones concretas.

Carlos de Sola Llera, basándose en las convenciones del Consejo de Europa, entiende que entre los países europeos existe un consenso sobre los siguientes principios $^{14}$ :

1) El interés del hombre tiene prioridad sobre los meros intereses de la sociedad y de la ciencia.

2) Las intervenciones en el ámbito de la medicina deben ser realizadas según las normas y los deberes de la profesión.

3) No se puede realizar ninguna intervención sobre una persona sin su consentimiento informado.

4) Toda persona tiene el derecho a ser informada sobre su salud o a renunciar a esa información.

5) El derecho nacional ha de desarrollar disposiciones especiales para proteger a los incapaces (menores de edad, adultos incapacitados y enfermos mentales).

6) En caso de urgencia puede realizarse una intervención sin el correspondiente consentimiento.

7) El cuerpo humano o sus partes no pueden ser fuente de beneficios.

8) Se han de establecer sanciones para los casos en que estos principios sean transgredidos.

Jacob Dahl Rendtorff y Peter Kemp en un importante libro que recoge los resultados del Proyecto EU-Biomed II, que aglutinó a investigadores de diversos países europeos, nos dicen que la persona es

13 Ibíd., 198.

14 Cfr. C. DE SOla LleRA: "Zur Struktur der 'Konvention zum Schutz der Menschenwürde und der Menschenrechte im Hinblick auf die Anwendung von Biologie und Medizin: Bioethik-Konvention" des Europarates", Jahrbuch für Wissenschaft und Ethik, vol. 1 (1996), 190. 
un punto clave, y entienden que los principios éticos básicos de Europa en Bioética y Bioderecho son los siguientes: 1) autonomía, 2) dignidad humana, 3) integridad y 4) vulnerabilidad, y que el marco de todos ellos es la solidaridad y la responsabilidad ${ }^{15}$.

\subsection{América Latina: Los principios de la bioética y los derechos humanos}

Manuel Velasco Suárez, profesor de medicina en la Universidad Autónoma de México, nos dice que la ética biomédica se está desarrollando en Latinoamérica en torno al principio primordial del respeto a la persona y a sus derechos humanos. Entiende que la ética biomédica contribuye a la humanización de la medicina observando «las normas preventivas de protección de la salud, el respeto al derecho de los pacientes (...) y vigilando el ejercicio de la justicia» ${ }^{16}$. Así pues, parece que los principios de no-maleficencia, beneficencia, autonomía y justicia también se defienden en esta amplia zona del mundo.

El principio fundamental es el respeto a la vida de la persona en la absoluta integridad personal, incluyendo todas las facultades y competencias individuales. Los principios de no-maleficencia y beneficencia son reconocidos claramente por el autor, pues dice que la ética biomédica «recuerda al médico que su trabajo consiste en hacer el bien siempre y nunca hacer daño alguno» ${ }^{17}$. También defiende el principio de autonomía plasmado en el «criterio del 'consentimiento informado' para cualquier situación donde la participación de ambas partes (médicopaciente; por ejemplo) es indispensable en la 'toma de decisiones' ${ }^{18}$. Para concretar las cuestiones relativas a la justicia dice que es necesario sopesar los dos modelos políticos contemporáneos: el socialista y el liberal capitalista.

Hernán L. Fuenzalida-Puelma considera que la bioética en general pretende el mejoramiento de la calidad de vida y el incremento de la capacidad de desarrollo individual y comunitario. En el ámbito biomédico este autor también percibe un aumento en la defensa de la autonomía de los pacientes. El consentimiento informado comienza a ser un requisito indispensable en la atención de la salud y los pacientes

\footnotetext{
15 Cfr. J. DAhl RendtorfF y P. Kemp: Basic Ethical Principles. In European Bioethics and Biolaw. Vol. I: Autonomy, Dignity, Integrity and Vulnerability, y Vol. II: Partners' Research, Institut Borja de Bioètica, Barcelona 2000.

16 M. VELASCO-SUÁREZ: "Bioética y derechos humanos", Journal International de Bioéthique / International Journal of Bioethics, vol. 6, nº 4 (1995), 281.

17 Ibíd., 283.

18 Ibíd.
} 
reclaman sus derechos en los casos de mala práctica. En Latinoamérica se ha quebrado la estructura paternalista y se desarrolla el nuevo cambio de orientación en la relación médico-paciente orientada por el principio de autonomía. Las cuestiones de justicia son también muy relevantes siendo la salud pública un elemento esencial de las políticas de salud. No obstante, debido a la escasez de recursos en estos países el autor solicita «que la influencia foránea sea orientadora mas no determinante de modelos de salud que no dicen relación con las características y limitaciones de un medio social determinado» ${ }^{19}$.

Hubert Lepargneur, teólogo moral de Brasil, entiende que los principios de la ética biomédica son tres: autonomía, beneficencia (que incluye no-maleficencia) y justicia. Considera que el principio de autonomia, que conecta con la defensa de la dignidad de la persona, es el principio dominante en la ética biomédica contemporánea. Este principio es el dominante por varios motivos: 1) la experiencia negativa de los experimentos nazis sobre las personas, 2) el avance de la tecnología, 3) la consideración de todos los ciudadanos como corresponsables, 4) el individualismo, 5) la disminución de la confianza en el médico.

Según Lepargneur existe otro motivo para exaltar el poder decisorio del paciente, muy fuerte en Estados Unidos pero inexistente en Brasil: «evitar la pesada responsabilidad civil y penal en la que incurre un médico $(. .$.$) por cualquier error o fallo que ocurra» { }^{20}$.

Lepargneur acepta, en general, estos principios, pero recuerda la importancia de complementarlos mediante una casuística 2. Considera necesario recuperar la orientación de las virtudes y sitúa en un lugar preeminente la virtud de la prudencia. La prudencia no sólo delibera a la luz de los valores y los principios existentes, sino que además observa las consecuencias de su decisión por si es necesario un replanteamiento de algunas cuestiones. En la actualidad se considera que los comités de ética asistencial han de tomar las decisiones en base a los principios de la bioética, pero si sus miembros no poseen la virtud de la prudencia la decisión no será éticamente aceptable.

Este autor comenta como debilidades del principio de autonomía el hecho de que no se puede aplicar cuando el paciente es incompetente y que es el médico quien ha de evaluar el grado de autonomía del paciente. No obstante, la autonomía es el fundamento de la dignidad de la

19 H. L. Fuenzalida-Puelma: "Impacto social de la bioética en América Latina", en Journal International de Bioéthique / International Journal of Bioethics, vol. 6, no 4 (1995), 285.

20 H. Lepargneur: "Força e Franqueza dos Princípios da Bioética", Bioética. Revista Publicada pelo Conselho Federal de Medicina, vol. 4, nº 2 (1996), 134. 
persona, y «la autonomía de la persona es (...) un atributo que cualifica el poder de decisión del individuo en relación con aquello que él considera como su bien» ${ }^{21}$. Recoge tradiciones kantianas y hegelianas para defender que la autonomía no significa aislamiento estático de un sujeto, sino que los otros han de ser considerados, por eso no cabe confundir la autonomía con la arbitrariedad o la licencia.

Nos dice que en Brasil florecen la hermenéutica y la casuística como complementos de los principios. Tanto la casuística como la orientación por principios han de articular la resolución de conflictos a través de la virtud de la prudencia. Propone la vuelta a la idea de prudencia de Tomás de Aquino, en la cual las razones prácticas se dirigen a escoger el principio que mejor concilia al individuo y al bienestar social en las circunstancias concretas.

\section{3. África: La fuerza vital y el comunalismo}

En África hay alrededor de 1000 pueblos con diferentes culturas. A pesar de esa variedad de pueblos y a pesar de la gran influencia de la religión, la cultura y la tecnología de Oriente y Occidente, Peter Kasenene afirma que existe un modo africano de ver el mundo. Así, por ejemplo, una creencia común en las tradiciones de África es que los antepasados, después de muertos, mantienen su autoridad sobre los vivos.

Recogiendo las ideas de Placied Tempels, un misionero belga en el Congo que escribió un importante libro sobre la filosofía bantú ${ }^{22}$, y las ideas de J. Mbiti sobre las religiones y la filosofía africana ${ }^{23}$, Kasenene señala dos principios éticos básicos del pensamiento africano:

1) El principio de la fuerza vital. El fin último de cada uno es adquirir vida, fuerza vital. La felicidad suprema es poseer la mayor fuerza vital y la peor desgracia la disminución de esta fuerza, que ocurre por la enfermedad, el sufrimiento, la depresión, la fatiga, la injusticia, la opresión y cualquier otro mal social o físico. «Lo que incrementa la vida o la fuerza vital es bueno; lo que la disminuye es malo» ${ }^{24}$.

\footnotetext{
21 Ibíd., 140.

22 Cfr. P. TEMPELs: Bantu philosophy. Presence Africaine, Paris 1959.

23 Cfr. J. MBITI: African religions and philosophy. Heinemann, Oxford 1969.

24 P. Kasenene: "African Ethical Theory and the Four Principles", en R. Gillon (ed.), Principles of Health Care Ethics, John Wiley and Sons, Chichester/Nueva York/Brisbane/Toronto/Singapur 1994, reimpr. 1996, 184.
} 
2) El principio del comunalismo. El valor clave para las sociedades africanas es la comunidad. Ser es pertenecer y un individuo existe colectivamente en términos de familia, clan y grupo étnico. Cuando sufre no lo hace solo, sino con su grupo. Cualquier cosa que le pase al individuo le pasa a todo el grupo y cualquier cosa que le pase al grupo le pasa al individuo. Una persona no puede considerar siquiera su vida como una propiedad puramente personal. Kasenene añade: «Por esa razón la salud de uno es un asunto de la comunidad, y se espera que una persona preserve su vida por el bien del grupo» ${ }^{25}$.

En las sociedades tradicionales africanas la salud significa integración personal y equilibrio con el entorno social.

Kasenene analiza entonces si los principios de Beauchamp y Childress se pueden aplicar al mundo africano con las siguientes conclusiones:

a) Autonomía. En este continente la autonomía, entendida como la capacidad de pensar y actuar independientemente está limitada por el énfasis puesto en la comunidad. Hacer algo sin considerar la opinión de la familia o la comunidad se considera antisocial. Para tomar decisiones «debe haber cooperación, y si es posible acuerdo entre todas las partes implicadas $»^{26}$. El problema es determinar quién decide cuando no hay acuerdo. Estas sociedades son elevadamente paternalistas, pues la comunidad restringe la autonomía del paciente cuando cree que éste está actuando contra sí mismo. «El bien del individuo y del grupo es más importante que la libertad personal o la autonomía» ${ }^{27}$. La intervención paternalista se justifica diciendo que la experiencia y conocimientos de los mayores deben beneficiar a los miembros más jóvenes o menos inteligentes de la comunidad que podrían no conocer las implicaciones de sus decisiones o acciones. Se espera que la persona se adhiera a las decisiones de la comunidad. En el cuidado de la salud tradicional el sanador y la familia deciden por el paciente.

Ibíd., 185.

Ibíd., 188.

Ibíd., 187. 
b) Beneficencia. Para promover la fuerza vital todas las personas tienen el deber de hacer el bien a sus vecinos. La generosidad, amabilidad, hospitalidad y caridad no son meras virtudes, sino deberes para preservar y aumentar la fuerza vital. Por el mismo motivo se valora de manera muy elevada el cuidado de la salud. Sin embargo, la persona que sufre una enfermedad contagiosa tradicionalmente es aislada o se le ayuda a morir, si pone en peligro la salud de la comunidad. «El bien del paciente es considerado en el contexto del bien de todas las partes implicadas, especialmente el bien de la familia inmediata del paciente» ${ }^{28}$.

c) No-maleficencia. El principio de la fuerza vital establece el deber de no causar daño, lesión o hacer algo que reduzca la fuerza vital de los miembros individuales de la comunidad o que amenace su existencia colectiva. Uno tampoco debe dejar de hacer aquello que podría detener el daño que está siendo causado a otros. Kasenene escribe: «En términos del cuidado de la salud, se requiere al sanador tradicional y a la comunidad que no hagan nunca daño al paciente a menos que sea en su mejor interés o por el bien de la comunidad $»^{29}$.

d) Justicia. La justicia es altamente valorada para mantener el orden social, la paz y la solidaridad y evitar la desintegración de la comunidad. Por el bien de la comunidad las necesidades de cada uno han de ser atendidas sin discriminación, pero también hay que tener en cuenta el lugar que cada persona ocupa en la comunidad. La justicia se entiende como lo que uno merece de acuerdo a sus necesidades y a su estatus en la comunidad. Pero hoy cada vez se pone menos énfasis en el estatus y más en las necesidades, así se entiende que «el estado tiene la obligación de ofrecer al menos un estándar mínimo de cuidados de la salud disponible para aquellos que lo necesiten» ${ }^{30}$. 


\subsection{Asia: Las relaciones, la familia y la comunidad}

\subsubsection{La orientación por el tipo de relaciones}

En el Este y el Sudeste de Asia las personas actúan en la dirección que enfatiza mantener buenas relaciones con otros. Gen Ohi lo llama la «orientación ética del tipo-de-relación». En Estados Unidos y en otros países occidentales prevalece en cambio la «orientación ética del tipo-deautonomía».

La orientación por el tipo-de-relación tiende a evitar la confrontación abierta con los otros. Esta orientación recoge las ideas de dos principios de ética biomédica. Según Ohi, «en los esfuerzos dirigidos hacia el mantenimiento de buenas relaciones con los otros, los principios éticos en juego son los de no-maleficencia y beneficencia» ${ }^{31}$.

Un ejemplo de esta orientación se comprueba en el uso ambiguo del «sí»y y el «no», que se puede observar no sólo en los japoneses, sino también en los habitantes de otros países de la zona, como Tailandia, Indonesia, Malasia, Vietnam, Camboya, China, Corea y Taiwán. Este uso ambiguo del «sí» y el «no» tiene por finalidad evitar el enfrentamiento.

Otra característica es que se oscurecen los límites de la privacidad de la persona, que está muy marcada en Estados Unidos y acompañada por una conciencia de derechos, autodeterminación y privacidad. Hasta hace unos años, era costumbre en Japón no llamar a la puerta antes de entrar, y esto todavía es hoy habitual en países como Indonesia. Resulta significativo que en Indonesia y Japón no exista una palabra nativa que corresponda a «privacidad».

El principio de no maleficencia tiene más peso que el de autonomía. Esto hace que haya una aversión cultural considerable hacia la posibilidad de redactar un documento escrito de directrices anticipadas. Según este autor, «articular las preferencias de uno en un documento podría ser considerado como una expresión de desconfianza hacia los otros miembros» ${ }^{32}$.

Una persona tiene que comportarse como un miembro bueno, consistente y respetable del grupo, incluso en los últimos momentos de la vida.

31 G. OHI: “Advance Directives and the Japanese Ethos", en H.-M. Sass, R. M. Veatch, and R. Kimura (eds.), Advance Directives and Surrogate Decision Making in Health Care. United States, Germany, and Japan. The Johns Hopkins University Press, Baltimore and London 1998, 176.

32 Ibíd., 179. 


\subsubsection{La relevancia de la familia y la comunidad}

Rihito Kimura reconoce que vivimos en una era de globalización de los valores, por eso considera ingenuo que se enfaticen las diferencias de la herencia cultural en las relaciones humanas, familiares y sociales. Es cierto que los valores culturales y éticos diferentes deben ser respetados, «pero la justificación de cualquier acto o conducta contra la dignidad humana y los derechos de la persona por motivo de las tradiciones culturales no es aceptable» ${ }^{33}$. Esta visión universalista de Kimura contrasta con su interpretación de los valores japoneses de la ética biomédica.

En la historia de Japón se encuentran modos de comportamiento aceptados socialmente en los que una persona se sacrifica por el bien de su emperador o de la nación japonesa, ejemplos de ello son la práctica del harakiri o los soldados kamikaze. Aunque estas prácticas han desaparecido, Kimura afirma que «nosotros los japoneses valoramos las metas comunales como más importantes que la mera vida biológica y tenemos una tendencia a sacrificar nuestras vidas individuales por ideales más ampliosı ${ }^{34}$.

La mentalidad tradicional japonesa del amae, que es un sentido de interdependencia, hace que la cuestión de la muerte no sea considerada como algo individual, sino en relación con la familia y el grupo social.

\subsubsection{Familia, interdependencia, naturalidad y cobertura social}

Todavía se considera una falta social grave para un ciudadano japonés actuar de manera individual sin considerar el punto de vista de la familia o de la comunidad. La actitud de la interdependencia o amae lleva a que uno confíe su cuidado a su familia y a su médico, asumiendo que ellos le darán el cuidado más beneficioso y adecuado. Es habitual que se oculte la verdad al paciente sobre su enfermedad y que se informe sólo a la familia. Esto ha llevado al actual paternalismo de los médicos y a la indecisión y dependencia de los pacientes. Tsuchida nos recuerda una característica fundamental de la ética biomédica japonesa: «La vida y la

33 R. KimURA, con la asistencia de L. Bishop: "Contemporary Japan”, en W. T. Reich (ed.), Encyclopedia of Bioethics. Revised Edition. Vol. 3, Simon and Schuster Macmillan, Nueva York/Simon and Schuster and Prentice Hall International, London, Ciudad de México, Nueva Delhi, Singapur, Sidney and Toronto 1995, 1503.

34 R. KimurA: "Death, Dying, and Advance Directives in Japan. Sociocultural and Legal Points of View”, en H.-M. Sass, R. M. Veatch y R. Kimura (eds.), Advance Directives and Surrogate Decision Making in Health Care. United States, Germany, and Japan, 188. 
muerte no son actos completamente privados, sino más bien conciernen a la comunidad entera de la cual uno es miembro»» ${ }^{35}$.

La ética biomédica japonesa tiene en cuenta los siguientes principios:

a) El recurso al consenso en el seno de la familia y en la comunidad. Un japonés normal piensa en su familia como la fuente de significado de su vida, su razón de ser. Es por ello natural que mucha gente piense que la familia es el agente principal en el proceso de toma de decisiones sobre la vida y la muerte. No obstante, desde la Segunda Guerra Mundial, la autoridad patriarcal se ha erosionado. Hoy el lugar de la autoridad ya no radica en el marido o en el padre. Cada familia tiene que tomar sus decisiones compartiendo sus puntos de vista sobre las decisiones difíciles. «Las personas se sienten perdidas sin el recurso a un consenso que pueda aceptar no solamente la familia del paciente, sino también la comunidad general»>

b) La noción de simbiosis de todos los seres vivos. Esta visión está basada en la convicción budista de que todos los seres vivos tienen espíritu y son interdependientes.

c) El deseo de muerte natural. El deseo de morir sin prolongaciones técnicas exageradas se basa en parte en el carácter japonés según el cual no es adecuado molestar a otros demasiado, especialmente sobre el cuidado físico de uno, y en parte en la visión tradicional de la naturaleza. La visión japonesa de la naturaleza se conecta con la noción de «destino», y lleva a pensar que la aceptación de la muerte es algo más humano que tratar de vivir más allá de lo que a uno le corresponde.

d) La cobertura universal de los cuidados de la salud. Todos los ciudadanos japoneses están cubiertos por el seguro nacional de salud, así un individuo no tiene que preocuparse por cuidados básicos de salud. Este seguro evita las coacciones que de otro modo podrían sufrir los encargados de tomar decisiones referentes a pacientes terminales. «Uno está libre, al menos en términos de medicina básica, de la preocupación financiera sobre quién pagará el tratamiento médico» ${ }^{37}$.

35 T. Tsuchida: “A Differing Perspective on Advance Directives”, 211.

36 Ibíd., 212.

37 Ibíd., 215. 


\section{Principios de la bioética inspirados en las grandes religiones del mundo}

\subsection{Los principios católicos}

El deber de respetar la vida humana se expresa en el Quinto Mandamiento de la Ley de Dios: «no matarás». Este mandamiento contiene las matizaciones indicadas en el Éxodo: «no hagas morir al inocente y al justo» ${ }^{38}$. Según el Catecismo de la Iglesia Católica, «la vida bumana es sagrada, porque desde su inicio es fruto de la acción creadora de Dios y permanece siempre en una especial relación con el Creador, su único fin. Sólo Dios es Señor de la vida desde su comienzo hasta su término; nadie, en ninguna circunstancia, puede atribuirse el derecho de matar de modo directo a un ser humano inocentes ${ }^{39}$. La ley moral prohíbe también negar la asistencia a una persona en peligro, y así, considera una falta grave que se acepte la existencia del hambre en el mundo sin esforzarse por contribuir a remediarla.

Aquellos cuya vida se encuentra disminuida o debilitada tienen derecho a un respeto especial. La eutanasia directa es moralmente inaceptable. Según el Catecismo, «una acción o una omisión que, de suyo o en la intención, provoca la muerte para suprimir el dolor, constituye un homicidio gravemente contrario a la dignidad de la persona humana y al respeto del Dios vivo, su Creador ${ }^{40}$. No obstante, la interrupción de tratamientos médicos extraordinarios o desproporcionados, evitando el encarnizamiento terapéutico, puede ser legítima. "Con esto no se pretende provocar la muerte; se acepta no poder impedirla. Las decisiones deben ser tomadas por el paciente, si para ello tiene competencia y capacidad, o si no por los que tienen los derechos legales, respetando siempre la voluntad razonable y los intereses legítimos del paciente» ${ }^{41}$. El Catecismo también afirma lo siguiente: «El uso de analgésicos para aliviar los sufrimientos del moribundo, incluso con riesgo de abreviar sus días, puede ser moralmente conforme a la dignidad humana si la muerte no es pretendida, ni como fin ni como medio, sino solamente prevista y tolerada como inevitable» ${ }^{42}$. Los cuidados paliativos deben ser alentados.

En la encíclica Evangelium vitae, Juan Pablo II ha tratado la cuestión del final de la vida. Allí rechaza la tendencia de las sociedades

\footnotetext{
38 Éxodo, 23, 7.

39 Catecismo de la Iglesia Católica, Asociación de Editores del Catecismo, editado en 1992, $3^{a}$ ed. 1994, parágrafo 2258, p. 559.

$40 \quad$ Ibíd., parágrafo 2277 , p. 564.

41 Ibíd., parágrafo 2278, p. 565.

42 Ibíd., parágrafo 2279, p. 565.
} 
desarrolladas contemporáneas a considerar el sufrimiento como algo insoportable de lo que hay que liberarse a toda costa. No obstante, recogiendo ideas de la Congregación para la Doctrina de la Fe, afirma que cuando la muerte se anuncia inminente e inevitable se puede en conciencia renunciar a tratamientos que solamente lograrían una prolongación precaria y penosa de la vida. Para ello es necesario «valorar si los medios terapéuticos a disposición son objetivamente proporcionados respecto a las perspectivas de mejora ${ }^{43}$. También recoge la idea de Pío XII según la cual es lícito suprimir el dolor por medio de narcóticos, aunque tengan como consecuencia la limitación de la conciencia o la abreviación de la vida, siempre y cuando la intención no sea causar la limitación de la conciencia o la muerte sino calmar el dolor de manera eficiente. En todo caso debe intentar mantenerse la conciencia del paciente lo suficiente para que pueda prepararse para el encuentro con Dios.

John Finnis y Anthony Fisher interpretan los principios de Beauchamp y Childress desde la perspectiva del catolicismo ${ }^{44}$. También lo hace Bernard Hoose ${ }^{45}$. Las conclusiones generales de estos autores son las siguientes:

a) Beneficencia. El médico debe promover la buena salud de sus pacientes y curar o prevenir sus enfermedades. Los médicos a menudo realizan cálculos para determinar el tratamiento más eficiente. Sobre estos cálculos, los bioeticistas católicos aconsejan aplicar el criterio de la proporcionalidad. La proporcionalidad nos lleva a buscar la opción que prometa maximizar los bienes como la vida, la salud o la alegría, frente a los males como la muerte, la enfermedad o la tristeza.

b) No maleficencia. La tradición exige no tratar a los otros como medios para nuestros propios fines. En el cuidado de la salud hay tres formas comunes de maleficencia: mentir, matar y mutilar. Sobre ello Finnis y Fisher comentan lo siguiente: a) Aunque decir la completa verdad puede ser a

\footnotetext{
43 Juan Pablo II: "Lettera Enciclica Evangelium Vitae del Sommo Pontefice Giovanni Paolo II ai Vescovi ai Presbiteri e ai Diaconi ai Religiosi e alle Religiose ai Fedeli laici e a tutte le persone di buona volontà sul valore e l'inviolabilità della vita umana", Medicina e Morale. Rivista di Bioetica e Deontologia Medica, 1995/4, parágrafo 65, p. 875.

44 Cfr. J. FINNIS y A. FISHER: "Theology and the Four Principles: A Roman Catholic View I", en R. Gillon (ed.), Principles of Health Care Ethics, 31-44.

45 Cfr. B. Hoose: "Theology and the Four Principles: A Roman Catholic View II", en R. Gillon (ed.), Principles of Health Care Ethics, 45-54.
} 
menudo destructivo o desalentador, mentir es siempre incorrecto. b) Alguien que acaba con la vida de otro con la intención de hacerlo se dice que mata «directamente». Acabar con la vida de un ser humano inocente viola siempre el principio de no-maleficencia y es siempre incorrecto. Algunos tratamientos están médicamente indicados y son moralmente exigibles (ordinarios) otros son opcionales (extraordinarios) y otros están contraindicados (inmorales). c) La no-maleficencia prohíbe la mutilación, incluso si es consentida. El principio de la totalidad, defendido por los moralistas católicos, afirma que la mutilación sólo es moralmente permisible si es necesaria para el bien de todo el cuerpo.

El problema es cómo evaluar los diferentes daños y beneficios implicados en un caso particular. Todas nuestras acciones tienen más de un efecto. A veces, al intentar alcanzar algo bueno, ocurre un efecto negativo. Para establecer si el efecto negativo se puede justificar ha sido común en los círculos católicos emplear el principio del doble efecto. Este principio dice que el efecto malo puede ser justificado si se dan las cuatro condiciones siguientes: a) el acto realizado es bueno en sí mismo, b) el efecto bueno no resulta del efecto malo, c) la persona que actúa intenta solamente el efecto bueno, y d) hay una razón proporcionada para causar el daño. Un ejemplo que suele ponerse del doble efecto es cuando una mujer embarazada tiene un tumor en el útero. La extracción del tumor tiene como consecuencia negativa la muerte del feto, pero la intención es salvar la vida de la madre y no hay modo de salvar la vida del feto.

El principio del doble efecto parece desafiar la idea de San Pablo, según la cual no hemos de hacer el mal para que venga el bien ${ }^{46}$. Los teólogos morales revisionistas entienden que San Pablo se refiere a los males morales. Los males físicos en sí mismos son ónticos o premorales, y sólo cuando les añadimos otros factores como la intencionalidad de la persona que los comete pasan a ser males morales. Por eso Hoose concluye: «Podemos decir, sin temor a contradecir a San Pablo, que un cirujano puede infringir tales males ónticos como el dolor o la mutilación sobre un paciente para que el bien pueda ocurrir, teniendo en cuenta, por supuesto, que

$46 \quad$ Cfr. Carta a los Romanos, 3, 8. 
los males ónticos implicados no sobrepasen a los bienes ónticos» ${ }^{47}$. El propio Tomás de Aquino decía que el uso de la violencia para defenderse frente a la violencia de otro era legítima siempre que el que se defiende pretenda sólo el bien de la autopreservación y uno use más fuerza de la requerida para alcanzar ese fin. Para los proporcionalistas suprimir la autonomía del paciente es un mal óntico.

c) Autonomía. Para el católico todas las personas son sagradas porque son presencia creada de Dios. El respeto que se requiere por la persona es algo más que respetar su autonomía, pero ciertamente la incluye. Por ello Hoose escribe: «Todos aquellos implicados en las profesiones del cuidado de la salud deben, en consecuencia, respetar los derechos de sus pacientes a la autodeterminación, y deben asegurar que a esos pacientes se les ha suministrado la información necesaria para las decisiones que necesitan tomar sobre el tratamiento o sus enfermedades» ${ }^{48}$.

Pero los ideales de autonomía hoy contienen mucho de inaceptable. A menudo implican o promueven un sueño de absoluta autosuficiencia, independiente de Dios, de la comunidad, de la razón o de la realidad. La privacidad y el derecho sobre el propio cuerpo ponen barreras para atender a los seres humanos de cuya existencia somos responsables. Propiamente entendida, la autonomía es un reconocimiento de la radical igualdad de todos los seres humanos, y la inalienable responsabilidad de todos los que pueden escoger alcanzar el desarrollo integral humano. Ciertas normas de la profesión sanitaria, como el respeto de los derechos del paciente, el consentimiento informado, o la confidencialidad, son muy sensatas, pero el principio de autonomía encierra también el peligro de convertirse en la fórmula para exterminar a muchas personas enfermas o discapacitadas, jóvenes y viejas. Si aceptamos el suicidio asistido o la eutanasia voluntaria en nombre de la autoliberación autónoma de una vida que resulta una pesada carga, entonces pronto se dirá que aquellos que no pueden dar su consentimiento no deben ser privados de su mismo derecho a la liberación de la pesada carga de la vida. «El 'derecho' será ejercido 'en su lugar' por

47 B. Hoose: "Theology and the Four Principles: A Roman Catholic View II", en Raanan Gillon (ed.), Principles of Health Care Ethics, 48.

48 Ibíd., 46. 
alguien que escogerá por ellos la muerte que, se supondrá entonces, ellos habrían (o deberían haber) escogido, si hubieran sido capaces de elegir. Un falso 'principio de autonomía' podría entonces ser el vehículo constitucional y ético para la profunda injusticia de una maleficencia 'beneficente', deshaciéndose la comunidad de muchas vidas consideradas 'no dignas de ser vividas'»".

d) Justicia. La famosa ley del talión, expresada en la frase «ojo por ojo, diente por diente», y que significa "devolved bien por bien y mal por mal", es transformada en el Nuevo Testamento por la ley: «amad a vuestros enemigos», es decir «devolved bien por mal». El justo es el que no juzga a los demás y se limita a bacerles el bien, con independencia del modo como los demás le traten a él. Aspira a que su ejemplo sirva para que los demás acaben también haciendo el bien.

En la Biblia encontramos un claro criterio para determinar los actos justos en la llamada Regla de Oro. Esta regla tiene en el Antiguo Testamento una formulación negativa y dice así: «lo que no quieras para ti, no lo hagas a nadie» ${ }^{50}$. Esta formulación se vuelve positiva en el Nuevo Testamento: «todo lo que queráis que hagan con vosotros los hombres hacedlo también vosotros con ellos $\rangle^{51}$.

Otra noción relevante de justicia bíblica la podemos encontrar en la referencia que en el Nuevo Testamento se hace al juicio final. Allí Dios separa a los justos de los pecadores. El criterio de esta separación es que unos han atendido a las necesidades de sus semejantes, pues dice: «tuve hambre y me disteis de comer, tuve sed y me disteis de beber... $\rangle^{52}$, mientras que los otros no lo han hecho. Parece percibirse aquí que el criterio de justicia para distribuir los bienes de una sociedad es la necesidad que algunos seres humanos pueden tener de ellos en un momento dado.

El cuidado de los débiles, de los enfermos y de los que sufren es uno de los mensajes principales del cristianismo. En este sentido la compasión es un valor fundamental. Según Finnis y Fisher, este valor no tiene nada que ver con

49 J. FINNIS y A. FISHER: "Theology and the Four Principles: A Roman Catholic View I", en R. Gillon (ed.), Principles of Health Care Etbics, 41.

50 Tobias $4,15$.

51 Mateo 7, 12 y Lucas 6, 31.

52 Mateo 25, 31-46. 
la eutanasia, «la compasión significa querer lo mejor para los otros, teniendo empatía con ellos en su sufrimiento, y buscando positivamente ayudarles con actos de misericordia en mantener su dignidad ${ }^{53}$. Hoose, en cambio, nos recuerda que en el cristianismo la vida es un valor básico, pero no un valor absoluto. Si el paciente está consciente pero con dolores extremos, y la prolongación de su vida únicamente supondrá una prolongación de su agonía y si el paciente quiere que se le permita morir debe respetarse su voluntad.

\subsection{Los principios anglicanos}

John Habgood ${ }^{54}$ nos recuerda las ideas básicas de la iglesia anglicana. Esta iglesia se compone de 27 provincias autónomas que cubren muchos países del mundo, sobre todo los países que pertenecen o han pertenecido a la Commonwealth y los Estados Unidos. El arzobispo de Canterbury actúa como foco de unidad, pero no tiene jurisdicción sobre ninguna otra provincia aparte de la suya. Los alrededor de 600 obispos anglicanos diocesanos se reúnen cada 10 años en la llamada Conferencia Lambeth, para tratar una gran variedad de asuntos teológicos y prácticos, sus resultados son sólo recomendaciones. Debido a esta estructura abierta, sus miembros a menudo expresan posiciones divergentes, aunque existe un núcleo común.

La iglesia anglicana apela a la guía de la escritura, la tradición y la razón. La escritura es el testigo definitivo de los acontecimientos que yacen en el corazón de la fe cristiana, la tradición es la sabiduría acumulada de la iglesia en la interpretación y la respuesta a esos acontecimientos, y la razón consiste en la reflexión sobre la escritura y la tradición a la luz del conocimiento disponible actualmente. El énfasis en la razón comporta la disposición para entrar en diálogo con la ética secular y para encontrar ideas comunes con otras religiones o tradiciones éticas no religiosas.

Uno de los mayores exponentes del pensamiento moral anglicano es Joseph Butler, expresado en los 15 sermones que ofreció a los miembros de la judicatura en la Capilla Rolls en 1726. Butler identifica tres tipos de acción: amor propio frío, benevolencia y consciencia.

53 J. FinNIS y A. FISHER: "Theology and the Four Principles: A Roman Catholic View I", en R. Gillon (ed.), Principles of Health Care Ethics, 42.

54 Cfr. The Most Reverend and Right Honourable John Habgood, "An Anglican View of the Four Principles", en R. Gillon y A. Lloyd (eds.): Principles of Health Care Ethics, 55-64. 
1) El amor propio frío (cool self-love) o autointerés ilustrado, como suele llamarse hoy, permite a los seres humanos mirar más allá de sus impulsos inmediatos y planear metas a largo plazo con el propósito de maximizar la felicidad.

2) La benevolencia controla las afecciones y aversiones hacia otros. Es propio de los seres humanos cuidar de los otros. Este principio no se contradice con el anterior. De hecho la práctica de la benevolencia puede conducir a una mayor felicidad como resultado a largo plazo.

3) La consciencia es la capacidad de la reflexión moral. De algún modo representa el bien de la vida humana. En cualquier jerarquía de principios la consciencia debe estar en primer lugar.

Habgood compara estos tipos de acción con los principios de la ética biomédica de Beauchamp y Childress.

1) Autonomía. Respetar la autonomía de las personas significa respetar su integridad como individuos libres y responsables, capaces de tomar decisiones sobre su propio futuro, respetar sus intereses y tratarlos desde el supuesto de que ellos saben mejor que nadie cuáles son esos intereses, y respetar su consciencia, entendida como expresión de la integridad de la persona. Sobre esta base hay fuertes argumentos para decir que «los pacientes pueden rechazar el tratamiento de soporte vital cuando es claro que no se puede esperar ningún beneficio sustancial de él y cuando la vida misma se ha vuelto demasiado pesada» ${ }^{55}$. Pero la eutanasia activa contiene más que eso, pues requiere a otra persona que acabe con la vida. Si hay límites dados por Dios a la autonomía han de yacer aquí, «en la aceptación continuada del regalo de la vida misma $\rangle^{56}$. La vida personal no es una posesión solitaria, e incluso el individuo más aislado está relacionado con los otros a través del mero hecho de existir como ser humano. La autonomía completa es un sin sentido pues lleva al individualismo, que es la negación de la moralidad. La vida humana florece en interdependencia con realidades que yacen fuera de ella. En lenguaje cristiano se dice que la libertad y la dignidad

Ibíd., 59.

Ibíd. 
humana no yacen en el yo individual, sino en la relación del yo con Dios.

2) Beneficencia y no-maleficencia. Estos dos principios van juntos. Butler acentúa la relación entre los principios morales y sus consecuencias actuales en términos del bienestar humano. Butler prescribe la benevolencia, pero ésta tiene como límites la justicia y la veracidad. «La necesidad de 'veracidad' nos puede alertar del peligro de la benevolencia que se desliza en sentimentalismo, o en esa sobre-protección hacia otros, que al final los despoja de su dignidad $»^{57}$. La maleficencia, por otro lado, no es necesariamente el resultado de la malevolencia. El daño puede producirse a veces como resultado de buenas intenciones. Por ello el juicio moral referido a las consecuencias de una acción determinada no puede tratar sobre la beneficencia o maleficencia, sino sobre la naturaleza de las personas, y sobre las relaciones de confianza que pueden subsistir entre ellas.

3) Justicia. En los cuidados de la salud, la cuestión de la justicia se centra principalmente en la distribución de recursos. Como hemos visto, Butler prescribe la benevolencia dentro de los límites de la justicia. Es consciente de que es imposible amar a la humanidad en su totalidad, por eso entiende la frase «ama al prójimo» como ama a aquellos con los que te encuentras, como el modo de ejercitar la benevolencia imparcial. Hay temas más amplios en juego en un sistema de cuidado de la salud costeado por el Estado. En el Reino Unido, la accesibilidad a los Servicios Nacionales de Salud a todos, y la igualdad de tratamiento dentro de él, son considerados por muchos como los principales indicadores de la justicia social. La justicia también nos recuerda que el bienestar de la población como un todo no debe olvidarse nunca. Pero el pensamiento anglicano tiende a afrontar estas cuestiones desde la comunidad local donde las personas se comunican unas con otras cara a cara.

\subsection{Los principios judíos}

El modelo judío de toma de decisiones en medicina está compuesto de una tríada: el médico, que tiene la obligación de tratar al paciente y de darle el mejor consejo médico, el rabino cualificado, que es requerido para

57 Ibíd., 61. 
resolver cualquier problema ético o legal que pueden encontrar el paciente o el médico, y el paciente, que tiene la obligación de buscar ayuda médica, y tiene autonomía para escoger al médico o al rabino que le deben aconsejar, y decidir en aspectos que no implican ser experto en medicina, o que afectan a la valoración de la calidad de vida.

La ética biomédica judía parte de varios supuestos básicos. Avraham Steinberg destaca los siguientes ${ }^{58}$ :

1) El judaísmo plantea responsabilidades, obligaciones, deberes y mandatos, más bien que derechos o el puro hedonismo.

2) Favorece la aproximación casuista, más bien que la adhesión a principios generales.

3) Se opone a la absolutización de cualquier precepto singular, que tenga preferencia sobre cualquier otro principio.

4) El estudio de la ética no se queda en un ejercicio académico, sino que hay que actuar en consecuencia.

5) La relación médico-paciente se considera una alianza en la que el médico tiene siempre la obligación de ayudar a los necesitados.

6) Considera que la búsqueda de atención médica por parte del paciente es un imperativo moral. Nadie tiene el derecho de rechazar un tratamiento considerado necesario y efectivo por una opinión competente.

7) La vida humana es sagrada y de valor supremo. Constituye uno de los principios más importantes del judaísmo. Cada vida humana es igualmente valiosa, por lo tanto matar a un paciente decrépito que se aproxima a la muerte constituye exactamente el mismo crimen de asesinato que matar a una persona joven y saludable.

La ética biomédica judía reconoce la importancia de los cuatro principios de Beauchamp y Childress, la problemática se halla en establecer una priorización entre ellos. Según Steinberg, sobre esos principios podemos decir lo siguiente desde el judaísmo:

1) Autonomía. En el judaísmo se combina la idea de la elección libre con la idea de que Dios determina las reglas y las acciones en el universo y supervisa los hechos humanos. Así pues, «la conducta y las acciones humanas no son ni absolutamente

58 Cfr. A. Steinberg: "A Jewish Perspective on the Four Principles", en R. Gillon y A. Lloyd (eds.), Principles of Health Care Ethics, 66-67. 
libres ni absolutamente predeterminadas; más bien son ambas, libres y determinadass ${ }^{59}$.

De acuerdo con la ley judía el médico está obligado a sanar y el paciente está obligado a buscar la salud, en consecuencia «el tratamiento médico no está ocasionalmente determinado por el deseo y el consentimiento del paciente, sino por hechos objetivos» ${ }^{60}$.

La autonomía del paciente es preservada, no obstante, en ciertas situaciones médicas: a) Si no está probado que el tratamiento sugerido es eficar, o si el tratamiento sugerido es claramente fútil, el paciente tiene el derecho a rechazar la iniciación de tales tratamientos. b) Si el tratamiento supone un gran sufrimiento, o complicaciones significativas, el paciente tiene el derecho a rechazar tal tratamiento. c) Si hay varias opciones médicas igualmente efectivas y una opción se prefiere por causas no médicas, el paciente tiene el derecho a rechazar tal opción.

2) No-maleficencia. El médico tiene que ayudar y sanar, pero nunca usar su conocimiento para dañar a otros. Steinberg comenta: «la perspectiva judía de no-maleficencia no sólo incluye la prohibición de dañar a otros, también prohíbe las acciones dañinas hacia uno mismo. A cada persona se le manda que vele por su propia salud y su vida, y está obligada a evitar el auto-daño, lesión o suicidio» ${ }^{61}$.

3) Beneficencia. «Beneficiar a un prójimo se considera uno de los preceptos más importantes en el judaísmo. No es opcional, es exigible» ${ }^{62}$. Un ejemplo de ello es el precepto «amarás a tu prójimo como a ti mismo» ${ }^{63}$.

4) Justicia. En el pensamiento judío, la justicia se equipara a la compasión, gracia, caridad, verdad, confianza, paz, equidad e integridad. La perspectiva judía de la justicia no es procedimental, sino substantiva, es decir, nos dice cómo la vida debería ser. En la toma de decisiones sobre cuidados de la salud, se decide primariamente de acuerdo con las siguientes reglas: «el primero que llega es el primero en ser servido es la regla básica; si dos pacientes se presentan simultáneamente -el que está en mayor peligro médico

Ibíd., 69.

Ibíd.

Ibíd., 70.

Ibíd., 71.

Levítico 19-18. 
tiene prioridad; si ambos son iguales en sus necesidades médicas- se estipula una jerarquía basada en el valor social»» ${ }^{64}$.

En un artículo del Jewish Compendium on Medical Ethics donde se analiza el consentimiento informado y la comunicación de un pronóstico infausto al paciente, se pueden extraer los principios básicos de la ética biomédica judía.

En ese artículo se dice que la primera regla de la medicina es no dañar al paciente ${ }^{65}$.

La beneficencia es un principio muy relevante. La relación médicopaciente es asimétrica. En esa situación el médico es el que mejor puede determinar cuál es el bien del paciente. Puede ocurrir que él no convenza al paciente y por eso, en esas situaciones, es importante la figura del rabino, para mediar entre el médico y el paciente. El rabino transmite más confianza y puede intimar más con el paciente. Mientras que el paternalismo del médico puede a veces parecer sospechoso al paciente, el consejo paternalista del rabino resulta fácilmente aceptado. El bien del paciente permite al médico ocultar a éste información que podría resultarle dura de soportar, así «el bienestar del paciente permanece como la consideración primordial para determinar lo que debe decirse ${ }^{66}$.

El principio de autonomía es poco relevante. Según este artículo, desde una perspectiva judía, el consentimiento informado no es un aspecto esencial de la práctica asistencial. La obligación del médico es sanar al paciente. Esta obligación del médico tiene un origen divino y, en consecuencia, es una obligación religiosa del paciente buscar y permitir que se le apliquen tratamientos encaminados a que recobre la salud. Así, el paciente que rechaza un tratamiento razonable y médicamente apropiado «está violando la confianza divina» ${ }^{67}$.

Por otro lado la toma de decisiones clínicas no es un derecho exclusivo del paciente. Las decisiones relevantes han de ser tomadas entre el paciente, el médico, el rabino y la familia del paciente, siendo especialmente determinante la opinión del médico.

64 A. Steinberg: "A Jewish Perspective on the Four Principles", en R. Gillon y A. Lloyd (eds.), Principles of Health Care Ethics, 72.

${ }_{65}$ Cfr. Jewish Compendium on Medical Ethics, "The Best Interest of the Patient: Canterbury Can Require Too Much”, en B. A. Brody y H. Tristram Engelhardt Jr., Bioethics. Readings and Cases. Prentice-Hall, Englewood Cliffs, Nueva Jersey 1987, 130.

66 Ibíd.

67 Ibíd., 129. 


\subsection{Los principios islámicos}

La Sharia - la ley islámica - se elabora entre los siglos X y XII d.C. y desde entonces sus principios se consideran eternos e inmutables. Las fuentes de la Sharia son cuatro: 1) El Corán, que contiene la palabra directa de Dios revelada al profeta Mahoma, 2) la Sunna, colección de dichos de Mahoma, 3) el consenso de los doctores de la ley sobre determinados temas, y 4) el razonamiento por analogía. Las tres primeras fuentes son de origen divino, la última es establecida por los hombres.

El razonamiento por analogía es un instrumento lógico que consiste en deducir nuevas reglas de comportamiento para afrontar situaciones inéditas a partir de casos análogos reconocidos en las fuentes precedentes de la Sharia. Es el tipo de razonamiento empleado para diseñar los principios de la ética biomédica islámica.

Temiendo que el pluralismo se perciba como un «relativismo» ético, el Islam muestra una imagen aproblemática de la ética biomédica. Ante los diversos dilemas que plantean la práctica asistencial y la investigación clínica ofrece la respuesta de la «verdadera religión», respuesta clara y definitiva, al contrario de lo que ocurre con las arbitrarias reflexiones filosóficas del «desorientado» Occidente. Respecto a los principios de Beauchamp y Childress, según nos dice Dariusch Atighetchi, los autores islámicos se limitan a referir su existencia «sin profundizar en una reelaboración o jerarquización de ellos a la luz de la doctrina jurídica islámica» ${ }^{68}$. Se trata además de una orientación fuertemente jurídica, tendente a encontrar una solución institucionalizada de los problemas, más que a incrementar la reflexión en la toma de decisiones.

Los principios de la bioética islámica son los siguientes ${ }^{69}$ :

1) El carácter sacro de la persona humana. La vida es un don divino que debe ser protegido desde su inicio. Pero la vida, aunque es un valor supremo, no es un valor absoluto o un derecho inalienable. En la visión islámica el hombre no es portador de derechos inalienables conectados a su propia naturaleza, pues el hombre es una criatura de Dios y sólo el Creador tiene verdaderos derechos.

2) El principio de necesidad. Este principio se basa en varios pasajes del Corán. La necesidad hace excepciones a la regla y convierte

\footnotetext{
68 D. Atighetchi: "La salute nell'Islam. Una panoramica sugli orientamenti in bioetica", Notizie di Politeia, vol. 13, no 47/48 (1997), 84-85.

69 Cfr. ibíd., 85-86.
} 
en lícito lo que a otras personas estaría probibido. El valor principal que se protege con ello es la vida.

3) El principio del «mal menor». El médico tiene la obligación de no dañar al paciente. Cuando sea inevitable intervenir debe escoger el menor de los males. Así, por ejemplo, podrá amputar una pierna encangrenada para salvar la vida del individuo.

4) El principio del «beneficio público». Mediante este principio, que recoge la idea del altruismo presente en el Corán, se antepone el interés de la comunidad sobre el interés del individuo.

No se percibe una valoración de la autonomía del paciente en estos principios. Quizá no esté de más recordar que la palabra «Islam» significa «sumisión», o «paz sumisa».

\subsection{Los principios budistas}

El budismo es una tradición tremendamente diversa, con más de 2500 años de desarrollo en Asia. R. E. Florida, nos dice que hay dos escuelas principales: 1) La vieja tradición, llamada Theravãda, «el camino de los ancianos», centrada ahora en Sri Lanka, Tailandia, Burma, e Indochina, más conservadora, y 2) la joven tradición, llamada Mahãyãna, «el vehículo amplio», que predomina en China, Corea, Japón y los Himalayas. Los Mahãyãna son menos literales en sus interpretaciones y un poco más liberales en sus prácticas, pero ambas comparten una tradición de tolerancia.

Sólo recientemente han empezado los budistas a diseñar una ética biomédica sistemática. Dos autores destacan en esta tarea: Pinit Ratnakul $^{70}$ y Shoyu Taniguchi ${ }^{71}$. Los principios fundamentales se derivan de la experiencia ilustrada de Buda, el fundador de la fe. Una de las ideas fundamentales es que si algo conduce al alivio del sufrimiento, entonces es adecuado hacerlo. La ética budista es esencialmente global, así el primer principio del budismo consiste en considerar que todos los fenómenos están interrelacionados. Otra idea importante consiste en afirmar que el lugar que una persona ocupa en el mundo, el destino de uno, e incluso el carácter, están predeterminados por los actos previos de uno o karma. Los actos torpes conducen a estados desafortunados y los actos hábiles tienen el

70 Cfr. P. RATNAKUL: Bioethics: an introduction to the ethics of medicine and life sciences. Mahidol University, Bangkok 1986.

71 Cfr. S. TAniguchi: A study of biomedical ethics from a Buddhist perspective, Tesis de grado, Graduate Theological Union and Institute of Buddhist Studies, Berkeley 1987. 
efecto contrario. Pero el budismo no es un sistema determinista fatalista, pues cada persona tiene considerable oportunidad para mejorar su propio destino, viviendo de acuerdo con el dharma - es decir, la ley o las enseñanzas de Buda-. Sobre los principios de la ética biomédica podemos decir lo siguiente:

Ratnakul describe la autonomía como la capacidad de un individuo de ordenar, planificar y escoger, entre diversas potencialidades humanas, el patrón de su propia vida, mientras respete las pretensiones correctas de los otros sobre él, y el cumplimiento de sus responsabilidades como agente moral. R. E. Florida escribe: «En la ética budista tradicional, la autonomía no es considerada como una categoría principal. No obstante, el énfasis budista en la responsabilidad de cada persona por su propio karma o carácter moral implica autonomía $\rangle^{72}$. Pero la noción moderna de autonomía ligada al individualismo va en contra del principio fundamental del budismo que insiste en la co-dependencia de todos los seres. Por ello Ratnakul prescinde del principio de autonomía. Los principios defendidos por este autor son los siguientes:

1) No-maleficencia o abimsã. Ratnakul nos dice que en una sociedad budista, la primera obligación es no dañar a otros. Matar a una persona es tanto más malo cuando más virtuosa era la persona muerta.

2) Justicia. Florida considera que no es fácil encontrar equivalentes en el budismo para conceptos como justicia o imparcialidad tal y como se entienden hoy en Occidente. Ratnakul sí que habla de un principio de justicia por referencia a la cual critica la situación de los pobres de Tailandia, que tienen muy poco acceso a los cuidados de la salud, comparados con los ricos, y dice que el Estado tiene el deber de ofrecer cuidados adecuados para cualquier persona que los necesite. Florida comparte este pensamiento, pero considera que no tiene una base firme en el pensamiento tradicional budista.

3) Compasión (karunã) y beneficencia. Para Ratnakul la compasión es uno de los cuatro principios centrales de la ética biomédica budista. Ciertos estados sublimes de la mente son cultivados en el budismo. Hay cuatro de ellos que son compartidos por todas las escuelas: la amabilidad cariñosa hacia todos los seres sentientes, la compasión por la infelicidad de otros, la alegría

\footnotetext{
72 R. E. FloridA: "Buddhism and the Four Principles", en R. Gillon y A. Lloyd (eds.), Principles of Health Care Ethics, 109.
} 
simpatética por la felicidad y la buena suerte de otros, y la ecuanimidad.

4) Veracidad. El cuarto principio que Ratnakul ve como esencial en la ética biomédica budista es la veracidad. Uno debe decir siempre la verdad al paciente. No comunicar la verdad se debe habitualmente a la negación o al temor por parte del personal sanitario, de que la comunicación de la verdad pueda debilitar o reducir las expectativas de vida del paciente. Según este autor, la práctica del paternalismo ocultando la verdad, es inaceptable para el budismo.

Michael Barnes ${ }^{73}$ describe los rasgos esenciales de la ética biomédica budista, especialmente aquellos principios que tienen relación con el final de la vida. Extrayendo las ideas fundamentales que recoge este autor podemos distinguir los siguientes principios:

1) El respeto por la vida humana. Es el principio fundamental de la ética budista, y solicita no quitar la vida. Esto no significa que la vida tenga que ser mantenida a toda costa. Es similar al principio de la «santidad de la vida» en la tradición cristiana.

2) La autonomía. Otro de los principios es la autonomía del sujeto moral, pues la persona acepta voluntariamente seguir a Buda. Algunos especialistas afirman que, en la ética budista, «el valor de la vida humana se encuentra en la capacidad para la elección consciente» ${ }^{74}$, es decir, en su autonomía.

3) La intención. La intención juega un papel central para determinar la altura moral de un acto. Una acción es inmoral si surge de estados mentales dominados por la avaricia, el odio o el engaño, mientras que la acción es moral cuando surge de estados caracterizados por cualidades opuestas. La calidad moral de un acto se determina por el estado interior del individuo. En el budismo es muy importante prepararse cuidadosamente para el momento de la muerte, pues esto determina la próxima reencarnación. El ideal es morir de modo consciente.

73 Cfr. M. BARnes: "Euthanasia: Buddhist principles", en G. R. Dunstan y P. J. Lachmann (eds.), Euthanasia: death, dying and the medical duty, en British Medical Bulletin. A Series of Expert Reviews, vol. 52, no 2 (1996), 369-375.

74 Ibíd., 369. 
4) Sabiduría y compasión. El valor de la compasión se sitúa junto al conocimiento. El budismo es una religión de la compasión preocupada por aliviar el sufrimiento de todos los seres sentientes. La sabiduría consiste en comprender que el sufrimiento es universal, y que nada existe con independencia de las demás cosas. Todos los seres sentientes viven dependiendo unos de otros. El sufrimiento de un ser humano no puede ser separado del sufrimiento de otro. El nivel de sabiduría de un ser humano está relacionado con la compasión que siente hacia los otros. La compasión se expresa mediante actos que tienen por finalidad hacer el bien a otros. Estos actos han de adaptarse a las necesidades individuales y a las circunstancias.

Pitak Chaicharoen y Pinit Ratanakul, profesores en la Universidad Mahidol de Thailandia, consideran que el concepto de la dependencia mutua o la interrelación podría constituir por sí mismo uno de los principios de la ética biomédica budista. Cuando todos los seres dependen de los otros seres, ninguno de ellos tiene prioridad, y la preocupación por los otros, la cooperación y la armonía son valores cruciales en las relaciones sociales. El «derecho a morir» reclamado por los defensores de la eutanasia, no puede ser absoluto, porque las personas no viven solas sino como miembros de comunidades que pueden resultar dañadas por su muerte o por una política social que anime a la muerte. Chaicharoen y Ratanakul comentan: «Respecto a las decisiones sobre la vida y la muerte los médicos y otros miembros del personal sanitario no deberían decidir un acto por ellos mismos sino en diálogo (partnership) con los pacientes, sus familias $y / 0$ representantes» ${ }^{75}$. Y añaden: «Por consiguiente, los médicos deben incluir en su ética profesional la necesidad de obtener el consentimiento de sus pacientes o representantes para cualquier tratamiento» ${ }^{76}$.

Según estos autores, la eutanasia activa viola el primer principio budista que prohíbe matar, pero podría justificarse la eutanasia pasiva, pues los médicos no han de prolongar indefinidamente el uso de las medidas de soporte vital. Se ha de tener en cuenta el coste médico para la familia, la escasez de los recursos médicos, la incerteza médica y la calidad de vida del paciente. Además en la actualidad se hace especial énfasis en la autonomía del paciente con el derecho a escoger o a

75 P. Chaicharoen y P. Ratanakul: "Letting-Go or Killing: Thai Buddhist Perspectives on Euthanasia", Eubios Journal of Asian and International Bioethics, vol. 8, $\mathrm{n}^{\circ} 2$ (1998), 39.

76 Ibíd. 
rechazar el tratamiento. El respeto a la autonomía del paciente se vuelve problemática cuando el paciente es incapaz. En ese caso es relevante la agonía de la persona y la futilidad del tratamiento para tomar decisiones.

\section{Conclusiones: hacia una bioética intercultural}

Una de las conclusiones más interesantes de Gillon ${ }^{77}$ sobre el tema que nos ocupa es que los principios de Beauchamp y Childress son universales. Las personas de diferentes culturas los interpretan de manera diferente, los armonizan, aplican o priorizan de modo diferente, pero constituyen un marco para analizar los problemas éticos en las ciencias biomédicas, son los «elementos de un lenguaje moral común» ${ }^{78}$. Yo comparto esa conclusión. En mi opinión, lo relevante en esta cuestión, no es tanto si se está a favor o en contra de los principios de la bioética. Lo relevante es que el debate en torno a ellos ha generado una reflexión sobre la bioética de carácter universal que, en la medida en que forma parte del lenguaje bioético en todas las culturas constituye, por lo tanto, una base importante para construir lo que podríamos llamar una «bioética intercultural».

Pero los principios de la bioética tienen otro potencial muy importante para ser la base de una bioética intercultural, y es su relación directa con los derechos humanos, defendidos con carácter universal.

Son varios los autores que piensan que existe un paralelismo entre los principios de la bioética de Beauchamp y Childress y los valores centrales que constituyen los derechos humanos, lo cual explicaría también por qué han formado parte del lenguaje común de la bioética internacional. Dos valores son centrales en la declaración universal de los derechos humanos: la libertad y la igualdad. Estos valores son los que deben orientar las decisiones en los conflictos de bioética. Así, María Casado escribe: «Los derechos humanos están llamados a ser el criterio regulador de las nuevas formas de control y de las posibilidades científicas y tecnológicas emergentes, propugnando, propiciando y garantizando el respeto a la libertad, a la igualdad y a la dignidad de todos y cada uno de los seres humanos» ${ }^{79}$.

\footnotetext{
77 Cfr. R. Gillon y A. LlOyd (eds.), Principles of Health Care Ethics, John Wiley and Sons, Chichester 1994, $2^{a}$ reimpr. 1996.

78 Ibíd., 333.

79 M. CASADO: "Los derechos humanos como marco para el bioderecho y la bioética”, en C. M $\mathrm{M}^{\mathrm{a}}$ Romeo Casabona (coord.), Derecho biomédico y bioética, Comares, Granada 1998, 118.
} 
La dignidad humana, junto al concepto de persona, posee un carácter central para articular los criterios a utilizar en el ámbito de la bioética. La especial dignidad del ser humano es el centro de la concepción ética y jurídica en que se basa la cultura occidental, y lo que hace al hombre especialmente digno frente a los otros seres es su libertad y las consecuencias derivadas del uso de la misma.

Haciendo referencia a la tercera generación de derechos humanos, inspirados en el valor de la solidaridad, esta autora añade que las nuevas situaciones deben ser también enfocadas desde el principio de la solidaridad, y no basta con las políticas públicas para hacerles frente, sino que se exige también el esfuerzo de la sociedad civil.

Esta autora acepta los cuatro principios de Beauchamp y Childress, pero lo que resalta es que tienen un paralelo en el ordenamiento jurídico: el respeto a los derechos humanos que toda persona posee y que no deja de tener por el hecho de convertirse en paciente. Así, «cuando en la reflexión bioética se habla del principio de autonomía y del principio de justicia, de lo que se está tratando es de libertad y de igualdad, de valores - y de derechos- que constituyen el núcleo de los derechos del hombre y de la tan nombrada dignidad humana» ${ }^{80}$.

Victoria Camps, por su parte, nos dice que la ética del siglo XXI tiene que ser una ética sin atributos: no una ética católica, evangélica, islámica, sino laica. Entendiendo por tal «una ética que procura valer para todos, independientemente de las diferencias culturales o ideológicas que separan a las personas y a los pueblos, y lo hace intentando aportar las respuestas más razonables» ${ }^{81}$. Las «razonables»son aquellas respuestas para las que tenemos razones, buenas razones o razones suficientes, que muchas veces no pueden ser nada más que razones compartidas. Por eso, la ética laica está fundamentada básicamente en el diálogo. «La mejor respuesta será aquella que resulte de la confrontación de opiniones diversas y que haya tenido en cuenta todas las opiniones discrepantes, en especial las de aquellos que pueden verse más afectados por el problema de que se trate» ${ }^{82}$.

Para esta autora no tiene sentido una diversidad ética absoluta, sin puntos de contacto y de encuentro que unan bajo un denominador común las distintas creencias o puntos de vista. Para lograr ese punto de encuentro sólo nos queda afinar en el procedimiento en la toma de decisiones correctas. Un procedimiento que consistirá en el diálogo, la discusión y la deliberación.

\footnotetext{
$80 \quad$ Ibíd., 127.

81 V. CAMPS: La voluntad de vivir. Las preguntas de la bioética. Ariel, Barcelona, 2005, 12.

82 Ibíd., 13.
} 
Camps nos recuerda que, al fin y al cabo, la moral tiene un origen común que podemos sintetizar en la llamada «regla de oro», y que se remonta a Confucio. Una regla popularizada con el dicho: «No hagas a los demás lo que no quisieras que te hicieran a ti». Es la regla del respeto y del reconocimiento mutuo, el reconocimiento de la dignidad intrínseca a cualquier ser humano.

Respecto a los principios de la bioética propuestos por el Informe Belmont - la beneficencia, la autonomía y la justicia, ya mencionados más arriba-, Camps afirma: «Tales principios no hacen sino traducir al lenguaje bioético los derechos humanos» ${ }^{83}$. Así, se le pide al profesional que se rija por el deber de hacer el bien, lo que, en principio, implica velar por la vida del paciente y restaurarle la salud. Pero, al mismo tiempo, dicho precepto se ve limitado por el respeto debido a la libertad de la persona, por una parte, y por la obligación de cooperar con una sociedad y unas instituciones que procuran ser más equitativas y justas. «El derecho a la vida, a la libertad y a la igualdad constituyen el subsuelo de los principios de beneficencia, autonomía y justicia» ${ }^{84}$.

Adela Cortina, por su parte, distingue entre éticas de mínimos normativos universalizables, que pueden ser defendidos con argumentos alcanzando intersubjetividad y éticas conciliatorias de máximos, referidas a la peculiar idiosincrasia de los individuos y los grupos, que han de ser respetadas en la medida en que no violen los mínimos universalizables. Así, «la ética de mínimos, fundada en la noción de autonomía, exigirá respetar los ideales de autorrealización de los individuos y los grupos, siempre que no atenten contra los ideales de los demás hombres» ${ }^{85}$.

El paciente, como interlocutor válido, tiene derecho a ser escuchado en la toma de decisiones que le afectan. Cortina afirma que «el consentimiento informado es la expresión del principio ético de la autonomía dialógica» ${ }^{86}$. No debe quedar en un mero requisito legal para cubrirse las espaldas ante cualquier posible denuncia, manera de actuar propia de la medicina defensiva. Es necesario reconocer que el paciente es un ser autónomo, cuya autonomía ha de ser respetada a través de la comunicación y el diálogo. Los afectados han de llegar a un «acuerdo

\footnotetext{
83 Ibíd., 15.

84 Ibíd.

85 A. CORTinA: "Ética del discurso y bioética”, en D. Blanco Fernández, J. A. Pérez Tapias y L. Sáez Rueda (eds.), Discurso y realidad. En debate con K.-O. Apel, Trotta, Madrid $1994,87$.

86 A. CORTINA: "Problemas éticos de la información disponible, desde la ética del discurso", en L. Feito Grande (ed.), Estudios de bioética, Universidad Carlos III de Madrid, Instituto de Derechos Humanos "Bartolomé de las Casas", Dykinson, Madrid $1997,54$.
} 
unánime» ${ }^{87}$, fruto de un diálogo sincero, en el que se busca satisfacer intereses universalizables.

El pluralismo razonable exige argumentar sobre una base compartida, y esa base es la ética cívica, que contiene valores como la autonomía, la igualdad, la solidaridad, el respeto activo y la actitud de diálogo.

Yo entiendo que sobre esta ética cívica, que contiene los valores fundamentales que inspiran los derechos humanos, y partiendo de los principios de la bioética, que a su vez traducen al lenguaje de la bioética dichos valores y derechos fundamentales, vemos surgir lo que podríamos llamar una «bioética intercultural», capaz de articular un lenguaje común entre las culturas, para afrontar los nuevos desafíos éticos que plantean las ciencias relacionadas con la salud y con la vida.

Sumario: Introducción; 1. Los principios de la bioética de Beauchamp y Childress en Estados Unidos; 1.1. Respeto de la autonomía; 1.2. Nomaleficencia; 1.3. Beneficencia; 1.4. Justicia; 2. Una mirada a los principios de la bioética desde Europa, América Latina, África y Asia; 2.1. Los principios de la bioética del Consejo de Europa; 2.2. América Latina: Los principios de la bioética y los derechos humanos; 2.3. África: La fuerza vital y el comunalismo; 2.4. Asia: Las relaciones, la familia y la comunidad; 2.4.1. La orientación por el tipo de relaciones; 2.4.2. La relevancia de la familia y la comunidad; 2.4.3. Familia, interdependencia, naturalidad y cobertura social; 3. Principios de la bioética inspirados en las grandes religiones del mundo; 3.1. Los principios católicos; 3.2. Los principios anglicanos; 3.3. Los principios judíos; 3.4. Los principios islámicos; 3.5. Los principios budistas; Conclusiones: hacia una bioética intercultural.

87 Ibíd. 